\title{
SUBSEA MULTIPHASE PUMPING SYSTEM X GAS LIFT: AN EXERGO-ECONOMIC COMPARISON
}

\author{
C. Y. Nakashima, S. Oliveira Jr.a, \\ and E. F. Caetanob, \\ ${ }^{a}$ University of São Paulo \\ Polytechnic School \\ Mechanical Engineering Dep. \\ Av. Prof. Mello Moraes, 2231 \\ Cidade Universitária \\ CEP 05508-900 - São Paulo, SP - Brazil \\ celyukio@usp.br, silvio.oliveira@poli..usp.br \\ ${ }^{\mathrm{b}}$ PETROBRAS - R\&D Center (CENPES) \\ Ilha do Fundao - Quadra 7 \\ CEP 21949-900 - Rio de Janeiro, RJ - Brazil \\ ecaetano@petrobras.cenpes.br
}

\begin{abstract}
This paper presents a methodology for an exergetic comparison between two artificial lift systems: a gas lift and a twin-screw multiphase pump system, and a standalone offshore platform. A software (Hysys.Process v2.1) was used to simulate an offshore platform with the artificial lift methods and calculate all properties (including exergy) of the material and energy streams. The twin-screw multiphase pump behavior was simulated with a thermodynamic model developed recently (NAKASHIMA (2000) and NAKASHIMA, OLIVEIRA and CAETANO (2002)). The operational conditions of the PETROBRAS 7MRL-72D-RJS well operating with cited systems were predicted by an internal study conducted in PETROBRAS (BARUZZI et al. (2001a) and partially published in BARUZZI et al. (2001b)). The comparisons cover the range of 2000 to 2020 , the same range adopted in the study. Results show that in general the production costs are lower when the multiphase pump is used. The main advantages of this method over the gas lift is the absence of material (gas) recycle and a better energy management.
\end{abstract}

Key words: Multiphase Pumps, Twin-Screw Pumps, Exergy Analysis, Petroleum Boosting, Artificial Lift Systems

\section{INTRODUCTION}

The influence of two artificial lift systems (SMPS and GL) on the petroleum primary processing is analyzed in this paper. Electricity, heat and production specific costs for an offshore platform operating with and without the help of auxiliary systems were calculated so their performance could be compared. The specific costs were calculated in an exergetic basis to allow a comparison in a rational way. Moreover, with the exergetic approach, it is possible to identify the main sources of irreversibilities (inefficiencies) and directly compare similar processes that occur in petroleum boosting systems. The evaluation of SMPS' performance among other alternatives is necessary since there are several intrinsic advantages and disadvantages associated to the SMPS. This must be assessed in order to establish the best operational conditions and scenarios for the best performance. The methodology for the exergy analysis of offshore platforms, developed earlier by OLIVEIRA and VAN HOMBEECK (1997), was completed with the inclusion of chemical exergy calculations.

\section{Twin-Screw Multiphase Pump}

The twin-screw multiphase pump is a positive displacement device with an axial flow through the screws. In this kind of pump, the rotation and meshing of the screws create one or more cavities which moves continuously from the suction to the discharge region (Fig. (1)). Therefore, any type of product (liquid, gas or solid) that can be introduced into the cavities will be carried along to the discharge. This characteristic allow the pump to transport multiphase fluids with GVF (gas volumetric fraction) varying from 0 to $95 \%(100 \%$ if $5 \%$ of liquid can be recirculated). By simultaneously "pumping" gas and liquid the multiphase pump could minimize facilities in deepwater and reduce operational costs, as cited by CAETANO et al. (1997). For example, PETROBRAS has a subsea system (SBMS-500) based in a twin-screw multiphase pump, which will be installed in the Campos Basin (see BARUZZI et al. (2001b)). Its objective is to increase well production through energy transfer to the unprocessed fluids. The use of twin-screw pumps is seen as a feasible option to make possible exploitation in ultra deep waters. The cost of a multiphase equipment (GONZÁLES and GUEVARA (1995)) can reach about $70 \%$ of the cost of a conventional equipment but the multiphase pump has lower efficiency (30 to 50\%) compared to the conventional pumps (60 to $70 \%$ ) and compressors (70 to $90 \%$ ). 


\section{TECNOLOGIA/TECHNOLOGY}

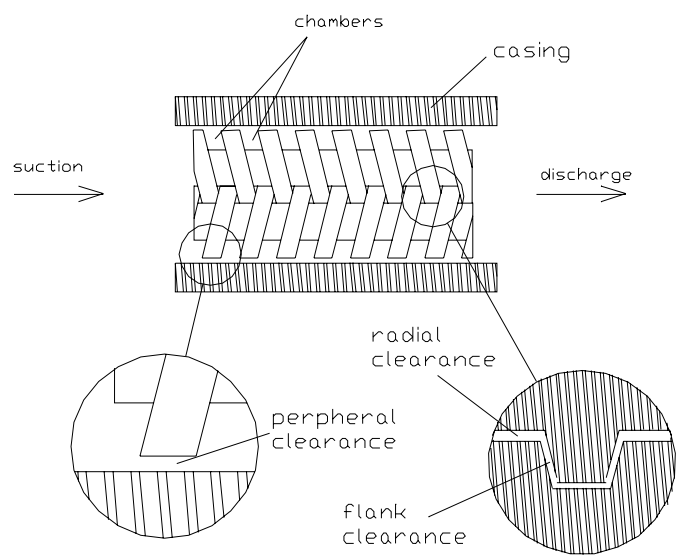

Figure 1. Twin-screw multiphase pump.

\section{Gas Lift System}

The gas lift system is the most common artificial lift method used in subsea petroleum boosting. In this system, part of the gas separated in the platform is recompressed with a gas lift compressor and returns to the well where it is downhole injected in the production column, as shown in Fig. (2). With this gas injection, the petroleum specific weight is reduced, the pressure in the well head is lowered and the production increases.

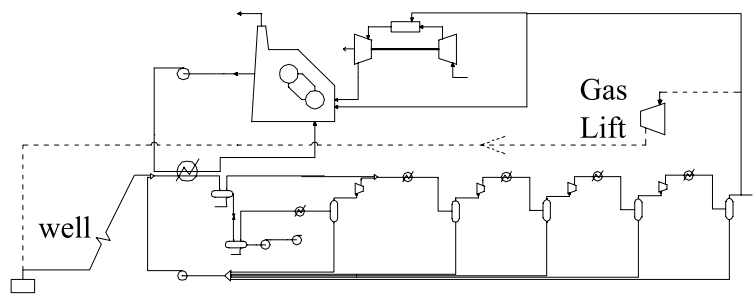

Figure 2. Platform/GL schematic process plant.

\section{Exergo-Economic Analisys}

The process plant of Marlim platform, which was used as basis to all comparisons in this paper, is represented in Fig. (3). The plant is fed with petroleum boosted from the well. This petroleum is mixed with the recirculated liquid and goes to the heat exchanger. The heated mixture proceeds to the separators where it is divided in oil, gas and water. Oil and gas are exported to the coast through pumps and compressors and part of the gas is separated to be used as fuel in a cogeneration system. The turbine is responsible for supplying electricity to pumps and compressors and

\section{Y. Nakashima et al. Subsea Multiphase Pumping...}

the rejected gases are used in the boiler to heat the water of the heat exchanger. Additional fuel is burned in the boiler when the rejected gases can not supply the required energy. The efficiencies used in the platform equipments for the simulations are as follows:

- isentropic efficiency of compression $\left(\eta_{\mathrm{cp}}\right)$ : 0.75 ; - mechanical efficiency of pump and compressors $\left(\eta_{m}\right): 0.90$;

- transmission efficiency $\left(\eta_{\mathrm{tr}}\right): 0.95$;

- isentropic efficiency of usual pumps $\left(\eta_{p}\right)$ : 0.75;

- thermal efficiency of gas turbines $\left(\eta_{\mathrm{tg}}\right): 0.30$;

- thermal efficiency of boiler $\left(\eta_{\mathrm{bo}}\right): 0.80$;

- heat recovery system thermal efficiency $\left(\eta_{\text {rec }}\right): 0.60$.

The methodology for exergy analysis of offshore platforms used in this paper, developed by OLIVEIRA and VAN HOMBEECK (1997), was further improved by the inclusion of chemical exergy calculations. The exergo-economic analysis was carried out by assuming a unitary value of the feed stream (i.e. well outlet stream) of the processing systems. The increment in the costs occurs only due to the irreversibilities associated with the processes. Both chemical and physical exergies must be calculated, otherwise an inconsistency would occur. The boiler and turbine use the gas chemical exergy in burning processes and the exergy balances would never be consistent without taking into account such values. The physical and chemical exergies were calculated with the software Hysys.Process v2.1. The chemical exergy, following RIVERO et al. (1998), is calculated through Eq. (1):

$$
\mathrm{B}_{\mathrm{ch}}=\sum_{\mathrm{i}=1}^{\mathrm{C}}\left(\mathrm{B}_{\mathrm{ch}, \mathrm{i}}^{0}+\mathrm{RT}_{0} \mathrm{x}_{\mathrm{i}} \ln \left(\mathrm{x}_{\mathrm{i}}\right)\right)
$$

Where $\mathrm{B}_{\mathrm{ch}}, \mathrm{B}_{\mathrm{ch}}{ }^{0}, \mathrm{~T}_{0}, \mathrm{R}$ and $\mathrm{x}_{\mathrm{i}}$ stand respectively for chemical exergy, standard chemical exergy, reference temperature, universal gas constant and molar fraction of component $i$.

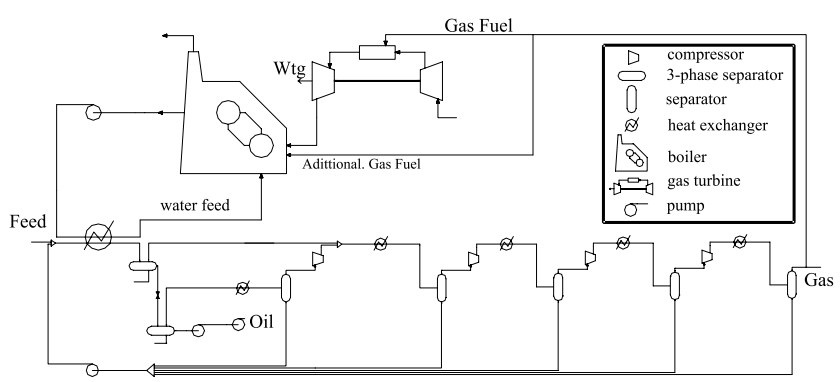

Figure 3. Process plant of Marlim platform. 


\section{TECNOLOGIA/TECHNOLOGY}

Equation (1) would be valid for ideal mixtures only. However, as shown by RIVERO et al. (1998), even though petroleum mixtures can not be considered ideal, the calculations with this equation do not cause significative errors due to the huge standard chemical exergies of the petroleum components. The standard exergy for the light components of the petroleum is tabulated in KOTAS (1985) The composition of the heavy fraction of petroleum is unknown. In this case, the heavy fraction is divided in pseudo-components and the standard chemical exergy of these components have to be calculated based on the net heating value (NHV):

$$
\alpha=\frac{\mathrm{B}_{\mathrm{ch}}^{0}}{\mathrm{NHV}}
$$

Where $\alpha$ can be calculated taking into account contaminants of petroleum (h - hydrogen, o oxygen and s- sulfur) through Eq. (3):

$$
\begin{aligned}
\alpha= & 1,0401+0,1728 \frac{\mathrm{h}}{\mathrm{c}}+0,0432 \frac{\mathrm{o}}{\mathrm{c}}+ \\
& +0,2169 \frac{\mathrm{s}}{\mathrm{c}}\left(1-2,0628 \frac{\mathrm{h}}{\mathrm{c}}\right)
\end{aligned}
$$

In this paper, it was considered that $\alpha$ has a constant value of 1.0401. The contaminants where not taken into account and the value $h / c$ for heavy fractions is generally about 0.1 . Therefore, its influence over $\alpha$ is less than $2 \%$. The heating value can be estimated using the equations suggested by GUTHRIE (1960).

The cogeneration system (gas turbine, boiler, heat exchanger and water pump) was simulated apart with EES (Equation Engineering Software). With the electricity and heating demands, it is possible to calculate the fuel consumption in the boiler $\left(\mathrm{B}_{\text {gas,bo }}\right)$ and the exergy associated to the streams of the cogeneration system. The power of the gas turbine $\left(\mathrm{W}_{\mathrm{tg}}\right)$ must be:

$$
\mathrm{W}_{\mathrm{tg}}=\frac{\mathrm{W}_{\text {total }}}{\eta_{\mathrm{m}} \eta_{\mathrm{tr}}}
$$

Where $\mathrm{W}_{\text {total }}$ is the power required by the pumps and compressors of the system. The exergy of the gas fuel of the turbine, $\mathrm{B}_{\text {gas, }, \mathrm{g}}$, is:
C. Y. Nakashima et al. Subsea Multiphase Pumping...

$$
\mathrm{B}_{\mathrm{gas}, \mathrm{tg}}=\alpha \frac{\mathrm{W}_{\mathrm{tg}}}{\eta_{\mathrm{tg}}}
$$

If the enthalpy flow rate of the turbine outlet gases cannot supply the thermal load, additional burn of fuel gas in the boiler must be provided. In this case, the exergy associated to the boiler fuel gas, $\mathrm{B}_{\text {gas,bo }}$, is given by:

$$
\mathrm{B}_{\mathrm{gas}, \mathrm{bo}}=\alpha \frac{\mathrm{Q}_{\mathrm{bo}}}{\eta_{\mathrm{bo}}}
$$

The exergy associated to the heat exchanged in the heat exchanger, $\mathrm{B}_{\mathrm{he}}$, is given by:

$$
\mathrm{B}_{\mathrm{he}}=\mathrm{Q}_{\mathrm{he}}\left(1-\frac{\mathrm{T}_{0}}{\mathrm{~T}_{\mathrm{mlt}}}\right)
$$

Where $\mathrm{T}_{\mathrm{mlt}}=154{ }^{\circ} \mathrm{C}$ is the mean logaritmic temperature of the heat exchanger, which is calculated through measured temperatures.

As the costs of electricity and rejects $\left(\mathrm{c}_{\mathrm{wel}}\right.$ and $\mathrm{c}_{\mathrm{rej}}$ respectively) are unknown in the turbine, a partition criterion -equality or extraction - must be adopted to allow calculations. In the equality method, the electricity and rejected gases are both considered products of the turbine and the cost increment is shared equally among them. The extraction method considers the electricity generation as the objective of the turbine and the cost increment is transferred only to the electricity by equalizing the costs of rejected gases and fuel. The heat cost $\left(\mathrm{c}_{\mathrm{Qhe}}\right)$ is calculated considering a control volume including the set water circuit/ boiler:

$$
\mathrm{c}_{\text {rej }} \mathrm{B}_{\text {rej }}+\mathrm{c}_{\text {gas }} \mathrm{B}_{\text {gas bo }}+\mathrm{c}_{\mathrm{wel}} \mathrm{W}_{\mathrm{wp}}=\mathrm{c}_{\text {Qhe }} \mathrm{B}_{\text {Qhe }}
$$

With these considerations, and having all exergies calculated, all the costs of the process can be calculated. It is an iterative calculation because the cost of the produced gas $\left(\mathrm{c}_{\mathrm{gas}}\right)$ must be used to calculate the costs in the cogeneration system.

Tables (1) and (2) show preliminary results, for three different turbine efficiencies $\left(\eta_{\mathrm{tg}}\right)$, used to choose the partition criterion. The obtained costs show a small increase between the feed and the discharge (oil and gas). This behavior is due to the 


\section{TECNOLOGIA/TECHNOLOGY}

high chemical exergy values. Compared to such values, the destroyed exergy in the equipment of the process is almost negligible and the increments are small. Only in the cogeneration system the cost increase is higher owing to the elevated irreversibility of the combustion process. The equality criterion seems to be more adequate for this study. First because both electricity and rejects are used in the process and second, as shown in Tab. (2), the reduction in the turbine efficiency cause, in the extraction criterion, a reduction in the cost of the produced oil. The cost increase, in this case, is transferred to the gas and this behavior is not adequate unless one consider the gas as the main product of the platform. Based on these results, the equality criterion was used for all the following calculations.

\section{SMPS x GL: Studied Cases}

In this paper, three systems and four different cases were compared: standalone offshore platform, GL and SMPS operating at two different operational conditions. The GL process plant used in the simulations is in Fig. (2). The GL was considered as a compressor that injects the outlet gas in the petroleum flow downhole in the well.

The SMPS is placed at the seabed, in the production line between the well and the platform. The SMPS have a broad range of operational conditions and two limit situations were chosen in this paper. The first one, denoted here as SMPS00 , is the SMPS working in order to give the same oil production obtained when the GL is used (dashed line in Fig. (4)). Due to the low flow rate, the multiphase pump operates far bellow its maximum capacity. In the second one, denoted as SMPS-60, the pump operates with the maximum allowable differential pressure (60 bar) with a higher flow rate (continuous line in Fig. (4)). Table (3) shows the operational conditions for the four cases. All these values refer to the production line position where the SMPS will be installed.

\section{Production Data}

Well production data with the use of artificial lift methods were reported by Baruzzi et al. (2001a). In the report the 7-MRL-72D- RJS well operating with SMPS or GL was simulated. SMPS discharge conditions and absorbed power were calculated by using a thermodynamic model for twin-screw multiphase pumps developed recently (NAKASHIMA (2000) or NAKASHIMA, OLIVEIRA and CAETANO (2002)). Geometric parameters of SBMS-500 were used for this purpose.

Table 1. Equality criterion - specific costs.

\begin{tabular}{|l|c|c|c|c|}
\hline \multirow{2}{*}{ Stream } & \multirow{2}{*}{$\begin{array}{c}\text { Exergy Flow } \\
(\mathrm{MW})\end{array}$} & \multicolumn{3}{|c|}{$\eta_{\mathrm{tg}}$} \\
\cline { 3 - 5 } & & 0.30 & 0.20 & 0.15 \\
\hline Feed & 4134.5 & 1.000 & 1.000 & 1.000 \\
\hline Oil & 3753.4 & 1.006 & 1.007 & 1.007 \\
\hline Gas & 329.2 & 1.025 & 1.027 & 1.028 \\
\hline Electricity & 6.3 & 1.932 & 2.085 & 2.140 \\
\hline Heat & 6.0 & 5.125 & 5.166 & 5.362 \\
\hline
\end{tabular}

Table 2. Extraction criterion - specific costs.

\begin{tabular}{|l|c|c|c|c|}
\hline \multirow{2}{*}{ Stream } & \multirow{2}{*}{$\begin{array}{c}\text { Exergy Flow } \\
(\mathrm{MW})\end{array}$} & 0.30 & 0.20 & 0.15 \\
\cline { 3 - 5 } & 4134.5 & 1.000 & 1.000 & 1.000 \\
\hline Feed & 3753.4 & 1.006 & 1.005 & 1.004 \\
\hline Oil & 329. & 1.034 & 1.048 & 1.061 \\
\hline Gas & 6.3 & 2.725 & 3.825 & 4.874 \\
\hline Electricity & 6.0 & 4.368 & 3.508 & 3.749 \\
\hline Heat & & & & \\
\hline
\end{tabular}

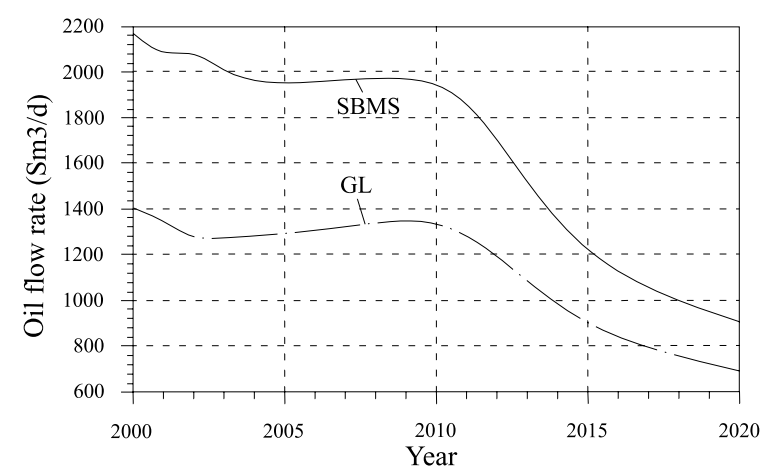

Figure 4. Volumetric oil flow: GL e SMPS-60 (after BARUZZI et al. (2001a).

SMPS electrical motor was set to 0.8 during calculations. This low value is due to the canned conception adopted for subsea operation. The GL compressor adiabatic efficiency was taken as 0.75 . Heat exchange between ducts and environment was not considered, nor was the electricity transmission efficiency of the SMPS energy cable. In this paper no operational limits were considered for any equipment involved in the petroleum processing. Which means that maximum or minimum rotation, power and flow rate were ignored. For all the simulations, some parameters were considered fixed: 


\section{TECNOLOGIA/TECHNOLOGY}

- Platform feed pressure: 21.6 barg;

- Gas pressure at platform outlet: 172.6 barg;

- Oil pressure at platform outlet: 67.6 barg;

- Well outlet flow's specific cost of: $1.0 \$ / \mathrm{kWh}$.

The specific costs were calculated for the years of 2000, 2001, 2010 and 2020. These years were chosen because the oil is considered the main petroleum product and, as shown in Fig. (4), the oil production has two distinct tendencies: one, between 2000 and 2010, where the production is kept almost constant, and the other, between 2010 and 2020, where there is a linear reduction in the oil flow. The year of 2001 was simulated because it is predicted a sudden increase in GVF in the first years which differs from the tendency of continuous decrease of the following years. With this increase the multiphase pump has to deal with a higher volumetric flow rate and, in the GL case, there is a lower necessity of lift gas. So, the behaviour of the systems suffers a considerable changeand are taken into account in the comparisons.

\section{RESULTS: Heat and Electricity}

Table (4) shows the total energy (heat and electricity) consumed in each case. These results show that heat consumption with the GL is slightly higher. This is due to the higher gas flow rate, a consequence of the lift gas recirculation. The difference is somewhat lower in 2001, because there is a decrease in the necessity of lift gas, and rise a little again in the following years. The heat consumption with the SMPS-60, which should be the highest values due to the high oil and gas flow rates, have a reduction in the first years owing to the higher shaft speed and friction power inside the pump. In 2020 the volumetric flow decreases with the consequent reduction in the shaft speed and friction power and the heat consumption raises.

The electricity consumption of the GL is driven mainly by the compressors consumption, which is large and approximately constant due to the lift gas. Despite its variation, the electric power of the pumps is a small part of total power and its influence is not significant. The electricity consumption of the SMPS goes along with the gas volumetric flow, which explains, in both cases, the initial increase followed by a reduction of the consumed electricity. With the SMPS-60, however, the electricity consumption is much higher. In this
C. Y. Nakashima et al. Subsea Multiphase Pumping...

case, there is a considerable increase in the mass flow of liquid and gas owing to the reduction in the well head pressure. The increase in the volumetric flow, however, is much higher due to gas expansion. The large volumetric flow, together with the elevated differential pressure, causes a higher power consumption as seen in Tab. (4). Due to the lower production, the platform has in general a lower consumption in pumps and compressors.

\section{Specific Costs}

Figures (5) and (6) show the feed and oil specific costs, in exergetic basis, calculated for the four studied cases. The standalone platform has always the lowest feed costs because there is no material or energy injection in the production column. However, when the oil cost is analyzed this behavior is not repeated. Only in 2001 has the platform the best cost because the well productivity is high even without auxiliary methods. In the other years, the oil cost for the SMPS method has lower values than the standalone platform. The higher feed cost is attenuated during the petroleum processing because SMPS provides an increase in petroleum production. The higher exergy flow, a consequence of the production increase, reduces the impact of energy expenses in the platform over the cost formation. In 2020, due to the extremely low production, the oil cost for the platform is the highest.

Comparing the GL and SMPS-00 cases, which have the same oil production, the resulting specific costs show that the SMPS-00 allows lower feed and oil specific costs. The main advantage of this system, when compared to the GL, is that there is not gas recirculation. The absence of this recirculation provides a reduction in the electric power consumed by the compressors, so the total electric power used in the platform is lower when the SMPS-00 is employed instead of the GL. With the GL, part of the produced gas will be burned to generate electricity that will be used to compress the gas again. The compressed gas is, then, reinjected downhole in the well in order to reduce the specific weight of the petroleum. In this case, besides the losses caused by successive conversions of energy, part of the gas is being processed (separated and compressed) in a redundant way since this gas, after previous processing, is recompressed and mixed again with petroleum. 


\section{TECNOLOGIA/TECHNOLOGY}

Related to this aspect, the SMPS-00 has an advantage because has no material (gas) recirculation. The electric power produced in the plant is transferred directly to the petroleum flow through the multiphase pump; there is no gas recirculation. Therefore, there is less gas to be processed by the separators and compressors, which causes a reduction in the consumption of heat and electricity. Another advantage of the SMPS-00 is its subsea operating position. This is a high pressure location and, compared to surface operations, allow the multiphase pump to work with lower volumetric flow and, so, lower energy consumption. These advantages, however, depend clearly on the amount of recirculating lift gas. In 2001, for instance, there is an increase in GVF due to reservoir characteristics and production

\section{Y. Nakashima et al. Subsea Multiphase Pumping...}

conditions - and a consequent lower necessity of lift gas. Within this scenario, the multiphase pump performance decreases and also decreases the impact of gas recirculation in the GL. The consequence is a reduction in the difference between SMPS-00 and GL production costs. In 2010 and 2020, with the opposite situation, the difference in production costs raises again. Therefore, the higher is the necessity of lift gas, the more advantageous is the employment of the SMPS for the studied well. The cost of the heat decreases as the electricity consumption increases. With the higher electricity demand, the turbine consumes more fuel and it is possible to have a further use of the rejected gases in heat generation. This means that more fuel is used to produce electricity and less fuel is burned in the boiler. The

Table 3. SMPS and GL operational conditions (Baruzzi et al. (2001a)).

\begin{tabular}{|c|c|c|c|c|c|c|c|c|c|c|c|c|c|c|c|c|}
\hline & \multicolumn{4}{|c|}{ Platform } & \multicolumn{4}{|c|}{ GL } & \multicolumn{4}{c|}{ SMPS-00 } & \multicolumn{4}{c|}{ SMPS-60 } \\
\hline Year & 2000 & 2001 & 2010 & 2020 & 2000 & 2001 & 2010 & 2020 & 2000 & 2001 & 2010 & 2020 & 2000 & 2001 & 2010 & 2020 \\
\hline $\mathrm{P}($ bar_g $)$ & 58.3 & 63.1 & 63.4 & 72.5 & 68 & 67.3 & 70.7 & 74.1 & 51.9 & 62 & 53 & 43.7 & 29 & 35 & 29.5 & 30 \\
\hline $\mathrm{V}(\mathrm{m} 3 / \mathrm{h})$ & 106.4 & 165.7 & 81.7 & 16.7 & 180 & 187.5 & 165.9 & 167.1 & 146.5 & 173.9 & 128.3 & 109.6 & 347.3 & 438.1 & 276.1 & 171.8 \\
\hline $\mathrm{GVF}$ & 0.53 & 0.65 & 0.40 & 0.21 & 0.65 & 0.68 & 0.59 & 0.59 & 0.57 & 0.66 & 0.47 & 0.38 & 0.73 & 0.79 & 0.65 & 0.49 \\
\hline $\mathrm{V}_{\mathrm{gl}}(\mathrm{Sm} 3 / \mathrm{h})$ & - & - & - & - & 4167 & 1667 & 4167 & 5833 & - & - & - & - & - & - & - & - \\
\hline$\Delta \mathrm{P}(\mathrm{bar})$ & - & - & - & - & - & - & - & - & 13.6 & 2.5 & 18.8 & 37 & 60 & 60 & 60 & 60 \\
\hline $\mathrm{W}(\mathrm{kW})$ & - & - & - & - & - & - & - & - & 83.1 & 33.5 & 99.1 & 174.3 & 645.1 & 822 & 519.1 & 346 \\
\hline
\end{tabular}

$\mathrm{P}$ - pressure, $\mathrm{V}$ - volumetric flow, $\mathrm{V}_{\mathrm{gl}}$ - lift gas flow, $\Delta \mathrm{P}$ - differential pressure, $\mathrm{W}$ - consumed electricity.

Table 4. SMPS \& GL - Heat and electricity consumption.

\begin{tabular}{|c|c|c|c|c|c|c|c|c|}
\hline \multirow{2}{*}{ Year } & \multicolumn{2}{|c|}{ Platform } & \multicolumn{2}{c|}{ SMPS-00 } & \multicolumn{2}{c|}{ GL } & \multicolumn{2}{c|}{ SMPS-60 } \\
\cline { 2 - 9 } & $\begin{array}{c}\text { Electricity } \\
(\mathrm{kW})\end{array}$ & $\begin{array}{c}\text { Heat } \\
(\mathrm{kW})\end{array}$ & $\begin{array}{c}\text { Electricity } \\
(\mathrm{kW})\end{array}$ & $\begin{array}{c}\text { Heat } \\
(\mathrm{kW})\end{array}$ & $\begin{array}{c}\text { Electricity } \\
(\mathrm{kW})\end{array}$ & $\begin{array}{c}\text { Heat } \\
(\mathrm{kW})\end{array}$ & $\begin{array}{c}\text { Electricity } \\
(\mathrm{kW})\end{array}$ & $\begin{array}{c}\text { Heat } \\
(\mathrm{kW})\end{array}$ \\
\hline 2000 & 654.9 & 1292.8 & 908.9 & 1330.3 & 1302.8 & 1581.4 & 2139.2 & 1170.6 \\
\hline 2001 & 1086.7 & 1441.7 & 1154.1 & 1402.5 & 1319 & 1510.8 & 2900.1 & 1025.3 \\
\hline 2010 & 482.9 & 1409.7 & 779.3 & 1591.7 & 1173.5 & 1856.4 & 1693.1 & 1562.8 \\
\hline 2020 & 71.5 & 703.3 & 551.9 & 1939.2 & 1066.6 & 2276.4 & 946.6 & 2038.3 \\
\hline
\end{tabular}

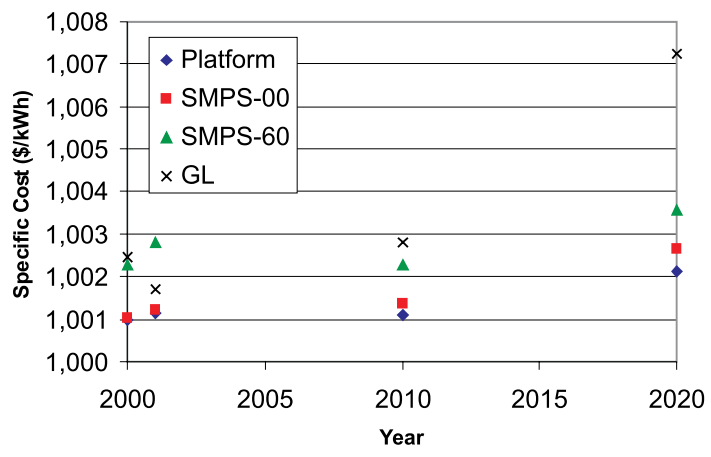

Figure 5. SMPS x GL - feed specific costs.

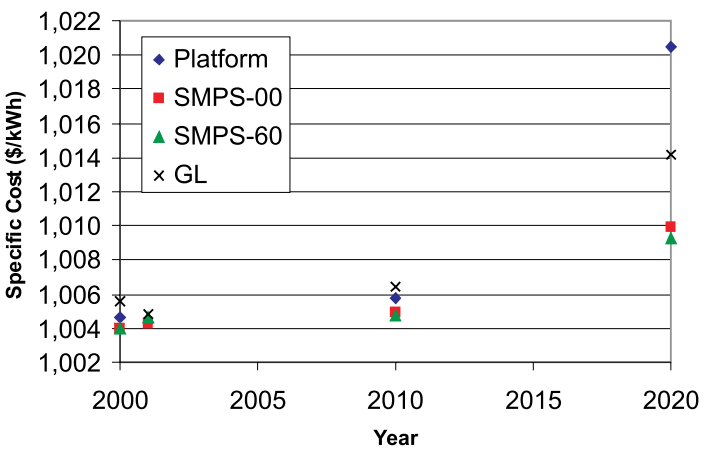

Figure 6. SMPS x GL - oil specific costs. 


\section{TECNOLOGIA/TECHNOLOGY}

better use of the gas fuel allows a reduction in the heating cost. The electricity cost has just a little fluctuation and follows the cost of the fuel gas.

By analyzing only the SMPS-00, one can see that the cost of the produced oil enhances continuously. In 2001, the small cost increment is due to performance degradation in the multiphase pump owing to high GVF. In 2010 and 2020, the increment occurs mainly due to the decreasing oil flow. The total (water + oil) liquid flow rate is kept almost constant - Fig. (3) shows only the oil flow rate - and the increasing flow of water causes a reduction in oil production and in the exergy associated with the petroleum flow. Therefore, the influence of electricity and heat costs over the stream is stronger. Physically this means that part of the energy inputs are consumed to process a substance with low value (water) which will not be part of the products. In the heating process, for instance, the water is heated, since it is part of the petroleum, and thrown away later on. The cost of the gas is lower with higher GVF because, in this case, the percentage of dissolved gas, which is more difficult to separate, is lower.

When the GL is considered, the gas and oil costs have a tendency to follow the magnitude of the lift gas flow. The higher is this flow, the larger are the costs. The lowest cost is obtained in 2001 when the necessity of lift gas is marginal. Before 2010 the lift gas flow raises again and, besides, the amount of water increases continuously as in the SMPS case. These two factors causes the costs to increase again.

The SMPS-60 has in general the same behaviour of the SMPS-00. However, as shown in the previous item, there is an increase mainly in the electricity consumption, which modifies the use of the energy inputs.

When the costs for the two conditions (SMPS-00 and SMPS-60) of the SMPS are compared (Figs. (5) and (6)), it is possible to see that the cost in the platform feed increases in the SMPS-60 case. Several parameters contribute to this increase: higher viscous losses due to higher shaft speeds, higher backflow rates due to higher differential pressures and higher GVFs, which causes higher internal recirculation inside the multiphase pump. The lower multiphase pump efficiency causes higher feed costs. However, when the oil costs are compared, it is possible to realize
C. Y. Nakashima et al. Subsea Multiphase Pumping...

that the SMPS-60 has lower costs despite of the higher feed values. Due to the high electricity consumption, all the heat required by the process is obtained from the turbine reject and there is no necessity of additional combustion in the boiler. This means that the gas is burned only to generate electricity (and increase production) and not to heat the petroleum.

\section{CONCLUSIONS}

The developed comparisons between GL and SMPS presented in this paper indicate that the employment of the SMPS could bring significant benefits in the offshore oil and gas production. When the costs of the produced oil are compared, the SMPS has always the lowest values, which means that the operational flexibility provided by the multiphase pump can be fully profited. With this flexibility it is possible manage the pump so the gas is burned only to generate electricity and increase the production while the heat is obtained entirely from the rejected gases. Such flexibility do not exist with the GL.

The advantage of the SMPS is much more evident when the GVF values are not so high. In this case, the multiphase pump performance increases and the need of lift gas is higher. When the GVF is high, the performance of the SMPS could be improved by installing the SMPS in a high pressure position (nearer the well head). This could reduce the volumetric flow and the power consumption (not considering the electricity transmission efficiency).

The cost values can change according to the platform configuration since the processes involved in petroleum production will define the costs. For different process plants it is necessary to evaluate the methods again. The production costs when the platform operates bellow its capacity would be higher by taking into account equipment and operational costs. With this fixed costs a lower production would have higher production costs. In theory, this would increase the advantage of the SMPS over lower productivity methods because it is possible to use the SMPS to fulfill the platform capacity. An exact evaluation, however, must take into account all the equipment and operational costs. 


\section{TECNOLOGIA/TECHNOLOGY}

\section{ACKNOWLEDEGMENTS}

Authors are thankful to: CTPETRO and PETROBRAS, for their support in the referred study and the permission to submit this paper to publication; the Chemical Eng. Department at USP, which allowed the use of the Simulation Laboratory and the program Hysys.Process v2.1; Soteica do Brasil S.A. and Eng ${ }^{\circ}$. Marcos Pereda in supporting the Hysys.Process v2.1 usage and Dr. J.R. Fagundes Netto (PETROBRAS) for the supplied information on fluid behaviour prediction.

\section{REFERENCES}

Baruzzi, J.O.A.; Fagundes Netto, J.R. and Caetano, E.F., 2001a, Operational Conditions Forecast for the SBMS-500 in the Well 7-MRL72D-RJS, Technical Partial Report. CENPES/ PETROBRAS.

Baruzzi, J.O.A., Caetano, E.F. and Fagundes Netto, J.R., 2001b, Production Forecast for a Subsea Multiphase Pumping System in the Marlim Field, SPE Annual Technical Conference and Exhibition, New Orleans, LA, Sept. $30^{\text {th }}$.- Oct. $3^{\text {rd }}$.

Caetano, E.F. ; Silva, R.M. ; da Silva, R.G. ; Camargo, R.M.T. and Rohlfing, G. , 1997, Petrobras and Bornemmann Pumpen Cooperation on Multiphase Flow Pumping. Proceedings of the 199729 th Annual Offshore Technology Conference, OTC'97, v.3, Houston, TX, USA, p. 109-118.

Gonzáles, R. and Guevara, E., 1995, Economic Field Development in Venezuela Heavy Oil Fields Using Multiphase Pumping Technology, Proceedings SPE International Oil Symposium, Richardson, TX, USA, pp. 195-201 (SPE 30262). Guthrie, V.B., 1960, Petroleum Products Handbook. McGraw Hill Book Company. London. Hyprotech , 1996, Hysys version 1.1 Reference vol. 1 e 2. Hyprotech Ltd.

Kotas, T.J., 1985, The Exergy Method of Thermal Plant Analysis, Butterworths, London.

Nakashima, C.Y., 2000, Thermodynamic Model of a Twin-Screw Multiphase Pump, MSc Dissertation, Polytechnic School of the University of São Paulo, 2000 (in Portuguese).

Nakashima, C.Y.; Oliveira Jr., S. and Caetano, E.F., 2002, Thermodynamic Model of a Twin-Screw Multiphase Pump, ASME Engineering Technology
C. Y. Nakashima et al. Subsea Multiphase Pumping...

Conference on Energy, Paper ETCE2002/PROD29164, February 4-6, Houston, TX.

Oliveira Jr., S. and Van Hombeeck, M., 1997, Exergy Analysis of Petroleum Separation Processes in Offshore Platforms. Energy Conversion and Management, v.38, No. 15-17, p. 1577-1584.

Rivero, R.; Rendón, C. and Monroy, L., 1998, Calculation of the Exergy of Crude Oil Mixtures, Proceedings of the International Congress ECOS'98, v.1, p. 211-218, July of 1998. 